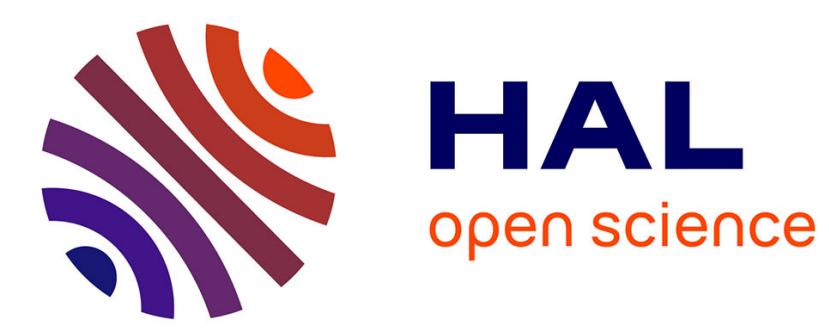

\title{
Using money to motivate both 'saints' and 'sinners': a field experiment on motivational crowding-out
}

\author{
Antoine Beretti, Charles Figuieres, Gilles Grolleau
}

\section{To cite this version:}

Antoine Beretti, Charles Figuieres, Gilles Grolleau. Using money to motivate both 'saints' and 'sinners': a field experiment on motivational crowding-out. [University works] auto-saisine. 2011, 17 p. hal-01499070

\section{HAL Id: hal-01499070 \\ https://hal.science/hal-01499070}

Submitted on 30 Mar 2017

HAL is a multi-disciplinary open access archive for the deposit and dissemination of scientific research documents, whether they are published or not. The documents may come from teaching and research institutions in France or abroad, or from public or private research centers.
L'archive ouverte pluridisciplinaire HAL, est destinée au dépôt et à la diffusion de documents scientifiques de niveau recherche, publiés ou non, émanant des établissements d'enseignement et de recherche français ou étrangers, des laboratoires publics ou privés. 


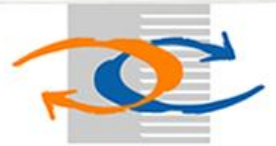

\section{A M E T A}

Laboratoire Montpelliérain d'Economie Théorique et Appliquée

U M R

Unité Mixte de Recherche

« Using Money to Motivate Both 'Saints' and 'Sinners' : A Field Experiment on Motivational Crowding-Out »

Antoine BERETTI

Charles FIGUIERES Gilles GROLLEAU

DR $n^{\circ} 2011-15$

Unite de Formation et de Recherche d'Economie Avenue Raymond DUGRAND C.S. 79606 34960 MONTPELLIER Cedex 2 Tel : 33 (0) 467158495 Fax : 33(0)467158467 E-mail : lameta@lameta.univ-montp1.fr 


\title{
USING MONEY TO MOTIVATE BOTH 'SAINTS' AND 'SINNERS': \\ A FIELD EXPERIMENT ON MOTIVATIONAL CROWDING-OUT
}

\author{
ANTOINE BERETTI, CHARLES FIGUIÈRES, AND GILLES GROLLEAU
}

\begin{abstract}
Economists recognize that monetary incentives can backfire through the crowding-out of moral and social motivations leading to an overall decrease of the desired behavior. We implement a field experiment where participants are asked to fill a questionnaire on pro-environmental behaviors under different incentive schemes, either with no monetary incentive (control) or with low or high monetary incentive directed either to the respondents or to an environmental cause. We investigate whether (i) there is a significant crowding-out effect, (ii) directing monetary incentive to the cause rather than to the respondents reduces the overall impact of a crowding-out effect, and (iii) offering the choice regarding the money recipient affects participation. Except for a high monetary incentive where the respondent chooses himself the end-recipient, we show that monetary rewards directed either at the individual or at the cause actually harms intrinsic motivations, but not to the same extent. We formalize our results building on an adaptation of an original model by Bolle and Otto (2010) and introduce agents heterogeneity in terms of intrinsic motivation. This heterogeneity has key implications for the understanding of the crowding-out effect. Several policy recommendations regarding the use of market-based instruments are drawn.
\end{abstract}

KeYwords: Crowding-out, heterogeneity, environmental regulation. JEL: Q50, D03, D04.

\section{INTRODUCTION}

Intrinsically motivated individuals frequently engage in activities for their own sake, without obvious external incentives. Governments and other organizations often use additional monetary incentives to reinforce or increase these intrinsically motivated activities. Nevertheless, several experiments showed that positive (negative) monetary incentives can be counter-productive, leading to a decrease (increase) rather than an increase (decrease) of the targeted activities (e.g., Titmuss,

Date: June 2011. 
1970; Frey and Oberholzer-Gee, 1997; Gneezy and Rustichini, 2000, Benabou and Tirole, 2006, Bolle and Otto, 2010).

This crowding-out of moral and social motivations by monetary incentives is relatively well-documented but empirical analyses of strategies to prevent it remain scarce. The originality of this paper is at least threefold. First, we implement a field experiment to investigate whether a crowding-out effect occurs in a context where intrinsic environmental motivations are presumably activated. Randomly selected household are simply invited to fill in a questionnaire on their proenvironmental practices under different incentive regimes, with commitment from us to associate any returned questionnaire a real proenvironmental action (to be detailed later). Second, we go further than most empirical papers which demonstrate the existence of crowding-out but don't suggest alternatives other than eliminating monetary incentives $^{(1)}$. Indeed, we explore whether the crowding-out effect is attenuated by using money for helping the environment per se rather than for rewarding the individuals. In addition, we investigate whether offering the choice to participants (rather than choosing for them) to direct the money to themselves or to the cause affects the spontaneous participation rate. Third, we take a step forward in the understanding and the analysis of the crowding-out effect, by postulating a heterogeneity of intrinsic motivations among contributors, from which we derive some important implications regarding the observability of crowding-out effects and regarding adequate policy designs.

The remainder of the paper is as follows. Section 2 positions our work in the literature. Section 3 constructs a behavioral model with heterogeneous agents, which will produce predictions that can then be confronted with facts. In Section 4, one finds a field experiment that delivers the following results. We show that in most cases (i) monetary incentives has a significant negative impact on participation, (ii) even when the monetary incentive is diverted to a pro-environmental association, the negative impact is weakened but participation remains lower (or similar) than without any incentive, and (iii) there is a relevant heterogeneity among agents in our experimental setting when considering their initial level of intrinsic motivation and thus their sensitivity to motivational crowding-out. The last section concludes with some policy implications and remarks.

\section{Contribution to the literature}

There is a sizable and growing literature, especially in psychology and economics (e.g., Deci et al., 1999; Frey and Jegen, 2001; Bowles, 2008; for reviews) where the crowding-out effect has been explored. Without purporting to be exhaustive, most papers can be classified along the

${ }^{(1)}$ On that subject, Falk (2007) suggests to offer gifts rather than money. 
following categories: (i) defining, debating and refining the concepts of crowding-out and intrinsic motivations and the circumstances under which this effect is likely to occur, (ii) testing empirically the existence and magnitude of crowding-out in different contexts.

While the theoretical possibility of crowding effects is widely accepted among economists, many of them have been critical about its empirical relevance, in spite of compelling evidence based on numerous circumstantial insights, laboratory studies and field experiments (Frey and Jegen, 2001). Simply put, external incentives can change the perceptions people have about a given task, notably by turning voluntary goodwill into a market-like interaction leading to a decrease of the overall contribution, contradicting the hypothesis of motivations additivity. In these cases, rather than reinforcing the pre-existing motivation, the crowding-out effect dominates the traditional relative price effect making the end-result counter-productive. The crowding-out effect is more likely to occur when (i) the external intervention is perceived as controlling rather than supportive, (ii) there is a high level of self-determination of individuals and (iii) there is a high level of trust between people (Vollan, 2008) ${ }^{(2)}$. Moreover, it has been shown that this effect lasts even after removing the monetary incentives and is contagious to fields which were not initially targeted by the external intervention. Nevertheless, recent empirical works showed evidence of the role played by the nature of external interventions. For instance, the field study conducted by Falk (2007) showed that including a postcard in a letter when asking for donation to support children in need generates a positive effect on donations. Unlike most empirical studies that simply discourage the use of monetary incentives in crowdingout sensitive contexts, we investigate an alternative strategy where monetary incentives are used but can be directed to the alleged cause underpinning the intrinsic motivation rather than to the individual.

In a recent contribution, Bolle and Otto (2010) shed a new light on the motivational crowding-out, linking the occurrence of crowding-out to the level of altruism of the average representative consumer. We go further by introducing heterogeneity in this conceptual apparatus. Some agents would thus have initial level of intrinsic motivation due to altruism and would therefore be sensitive to crowding-out effects, while some others would have no initial level of intrinsic motivation due to the absence of altruism and therefore would not be subject to

\footnotetext{
${ }^{(2)}$ Interestingly, most empirical studies have examined the effects of positive monetary rewards (e.g., Frey and Oberholzer-Gee, 1997; Mellström and Johannesson, 2008) while some scarce studies have considered the case of negative rewards (e.g., Gneezy and Rustichini, 2000). For example, Frey and Oberholzer-Gee (1997) found that acceptance of "not in my backyard" projects is reduced if monetary rewards are offered and Gneezy and Rustichini (2000) showed that a fine for picking children up late from day care increased the number of late pick-ups.
} 
crowding-out. Considering this heterogeneity regarding intrinsic motivations in the studied population authorizes an alternative approach of the crowding-out effect based on a trade-off between two types of contribution : an intrinsically motivated contribution, labelled 'green' and a non-intrinsically motivated contribution, labelled 'grey'. For the sake of simplicity, we will use the labels 'green' and 'grey' in the remainder of this paper. The possibility of a crowding-out effect thus relies only on the presence of a 'green' contribution, that could be fragile when facing a monetary incentive. We contend that an overall measure of the aggregated effect ignoring heterogeneity would suggest a 'one-size-fitsall' policy, while considering heterogeneity could allow policy makers to design and implement a better tailored incentive policy.

Furthermore in their experimental design Bolle \& Otto (2010) consider the correlation between a stated contribution to the provision of a public good (blood donation to the Red Cross) and the level of altruism (money donation to charity). This differs from our approach in that their subjects state their preferences about an hypothetical contribution under hypothetical incentive schemes, while in our experimental setting, subjects are revealing their preferences through a real contribution under real incentive schemes.

In sum, two points related to heterogeneity are worth noting: (1) the crowding-out effect can occur only in situations where green contributions are at stake, and (2) this effect is observable at the aggregated level only if the relative size of 'green' contribution is sufficiently larger than the 'grey' one. One must keep in mind that the green/grey contribution ratio is a key variable ${ }^{(3)}$.

\section{Crowding-out with heterogenous agents: A simple MODEL}

In this section we construct a simple behavioral model with heterogeneous agents in which it is possible to explore the logical implications of external monetary incentives on contributions.

Departing from the conventional rationale where self-interested individuals do not contribute to environmental public goods management, voluntary contributions such as volunteerism or donations are common in real-world settings. Assuming the existence of intrinsic motivations in the environmental realm (Reeson and Tisdel, 2008), we investigate

${ }^{(3)}$ To complicate even further the matter, the nature of the contribution and the type of the public good considered can have a critical influence on the share of intrinsically motivated agents within the population. There might even be no intrinsic motivation attached to the contribution in some given domains. Furthermore the persistence of crowding-out when the incentive is withdrawn shows that even in identical settings this ratio is not stable over time for a given population (Gneezy and Rustichini, 2000) 
whether monetary incentives undermine them and whether directing money to an environmental cause reduces the risk of crowding-out.

In the kind of situation we analyze in this paper, people know that they affect each other by their decisions, but their interactions are largely anonymous. They clearly don't know the set of strategies of the other individuals, nor do they know the utility functions of others. Actually they even ignore how many "others" there are. Therefore we prefer to analyze the issue using a "decision-theoretic approach", in close connection with the work of Bolle \& Otto (2010), rather than with a "game-theoretic approach".

There are $n$ agents. Each agent $i(i=1, \ldots, n)$ is endowed with an exogenous income $y_{i}$. He can contribute $x_{i}$ units of time to some environmental cause. His preferences, defined over bundles $\left(x_{i}, y_{i}\right)$, are captured by the following utility function:

$$
U^{i}\left(x_{i}, y_{i}\right)=y_{i}+a_{i} t^{*} x_{i}-c\left(x_{i}\right)
$$

In the above expression:

- $c($.$) is the cost of contribution. The standard assumption is that$ this cost is an increasing and convex function of $x_{i}: c^{\prime}(\cdot)>0$ and $c^{\prime \prime}(\cdot) \geq 0$.

- $t^{*}$ is agent $i$ 's estimation of the marginal benefits produced by his contribution $x_{i}$ on the other agents,

- and $a_{i}$ is a parameter that captures an attitude towards the other individuals via the environment, a sort of ecologicallymediated, or 'green', altruistic concern. In this respect there are two kinds of agents: $n_{1}$ of them do not feature any environmental concern, and are labeled grey, with $a_{i}=0$; the remaining $n_{2}=n-n_{1}$ agents have an ecological conscience, and are labeled green, with $a_{i}=a>0$. Those agents typically contribute voluntarily to the environmental cause. To be consistent with this feature, we therefore assume $a$ and $t^{*}$ are such that $a t^{*}>c^{\prime}(0)$.

We now study the effects of different incentive schemes on contribution.

3.1. Neutral Treatment. In the neutral treatment there is no incentive scheme. Individuals choose their contributions so as to maximize (1). Hence:

- grey agents typically settle for corner decisions:

$$
\frac{\partial U^{i}}{\partial x_{i}}=-c^{\prime}\left(x_{i}\right)<0 \Longrightarrow x_{1}^{N}=0
$$


- whereas green agents commit to positive contributions:

$$
\frac{\partial U^{i}}{\partial x_{i}}=a t^{*}-c^{\prime}\left(x_{i}\right)=0 \Longrightarrow x_{2}^{N}>0 .
$$

In aggregate, contributions are:

$$
X^{N}=n_{1} x_{1}^{N}+n_{2} x_{2}^{N}=n_{2} x_{2}^{N} .
$$

3.2. Direct Treatment. When individuals are paid for their contribution to the environment their utility function becomes:

$$
U^{i}\left(x_{i}, y_{i}\right)=y_{i}+w x_{i}+a_{i}\left(w+\varepsilon_{D}\right) x_{i}-c\left(x_{i}\right)
$$

where $w$ is the monetary transfer per unit of participation. It is crucial to note that such an instrument leads the agents to revise their estimation of the benefits of their contribution on others, which is now $w+\varepsilon_{D}$ instead of $t^{*}$. The idea is that the presence of a monetary transfer acts as a signal of the value of participation (Bolle and Otto, 2010), upon which individual estimations can be anchored. Moreover we assume that the estimation is at least equal to the payment offered $\left(\varepsilon_{D} \geq 0\right)$. Individuals can reasonably conjecture that the monetary transfer does not exceed the "true" value of the service offered. To be consistent with a crowding-out phenomenon among green agents, we assume a sufficiently high initial level of intrinsic motivation, in the sense $w+a\left(w+\varepsilon_{D}\right)<a t^{*}$.

With this incentive scheme, the two kinds of agents now pick up interior decisions. The individual contributions are modified as follows:

- for grey agents:

$$
\frac{\partial U^{i}}{\partial x_{i}}=w-c^{\prime}\left(x_{1}\right)=0 \Longrightarrow x_{1}^{D}>0,
$$

- for green agents:

$$
\frac{\partial U^{i}}{\partial x_{i}}=w+a\left(w+\varepsilon_{D}\right)-c^{\prime}\left(x_{i}\right)=0 \Longrightarrow x_{2}^{D}>0 .
$$

This scheme increases the contribution of grey agents, whereas it decreases the contribution of green agents $\left(x_{2}^{D}<x_{2}^{N}\right)$. And in aggregate the net effect on contributions is ambiguous; it depends both on the relative size of each type of contribution in the overall contribution and on the extent to which green agents have cut down their contributions. Formally:

$$
X^{D}=n_{1} x_{1}^{D}+n_{2} x_{2}^{D},
$$

and clearly,

$$
X^{D} \leq X^{N}=n_{2} x_{2}^{N} \Longleftrightarrow n_{1} x_{1}^{D} \leq n_{2}\left(x_{2}^{N}-x_{2}^{D}\right) .
$$

A crowding-out effect is observable when the aggregate gain on grey agents - who start to contribute - does not compensate the aggregate loss on green agents who are now contributing less. 
3.3. Indirect Treatment. The payment is no longer given to contributors; rather it is directed to a cause supporting the environment, for example a related association. Hence individual $i$ understands that each unit of time he concedes generates: $i$ ) as before a marginal benefit to the environment, $i i$ ) and an additional input due to the amount of money which does no longer go in his pocket but to the association.

The utility functions are now:

$$
U^{i}\left(x_{i}, y_{i}\right)=y_{i}+a_{i}\left[w+\left(w+\varepsilon_{I}\right)\right] x_{i}-c\left(x_{i}\right)
$$

where $w+\varepsilon_{I}$ is the corrected individual estimation of benefits on others.

Regarding the fact that a payment is directed to the cause supported by the individual, we can reasonably consider that the individual estimation of the benefit on others of his participation is higher than when the same amount of money is directed to the individual's pocket, because the chosen destination, by its very nature, reinforces the belief of the agent on the presence of high environmental values, or because the association is more efficient than individuals in transforming a given amount of contributions in environmental gains. An assumption on parameters consistent with that view is $a\left(2 w+\varepsilon_{I}\right)>w+a\left(w+\varepsilon_{D}\right)$.

Agents' decisions are as follows:

- grey agents:

$$
\frac{\partial U^{i}}{\partial x_{i}}=-c^{\prime}\left(x_{i}\right)<0 \Longrightarrow x_{1}^{I}=0
$$

- green agents:

$$
\frac{\partial U^{i}}{\partial x_{i}}=a\left(2 w+\varepsilon_{I}\right)-c^{\prime}\left(x_{i}\right) \Longrightarrow x_{2}^{I}>0 .
$$

Under this scheme, grey agents keep on contributing nothing, whereas green agents contribute more than under the direct treatment (but possibly less than under the neutral treatment provided that $\left.2 w+\varepsilon_{I}<t^{*}\right)$. In aggregate:

$$
X^{I}=n_{1} x_{1}^{I}+n_{2} x_{2}^{I}=n_{2} x_{2}^{I},
$$

and the superiority of one treatment over the other depends in particular on the relative size of grey and green agents. Indeed:

$$
X^{I} \leq X^{D} \Longleftrightarrow n_{2}\left(x_{2}^{I}-x_{2}^{D}\right) \leq n_{1} x_{1}^{D}
$$

To sum up, a switch from a direct payment to an indirect payment:

- generates losses on grey population, $n_{1}\left(x_{1}^{D}-0\right)>0$,

- generates gains on green population, $n_{2}\left(x_{2}^{D}-x_{2}^{I}\right)<0$.

- The aggregated effect thus appears to be ambiguous. Other things equal, overall participation is reduced (resp. increased) when $n_{1}$ is large (resp. small) compared to $n_{2}$ and/or when $a(1+w) t_{I}^{*}$ is close to (resp. far from) $w+a t_{D}^{*}$. 
3.4. Choice Treatment. Under this treatment, individuals can choose whether the payment is directed to themselves or to an environmental association. Giving the choice to individuals (keeping the reward for themselves or giving it to the 'environmental cause') can motivate both groups of intrinsically and extrinsically motivated individuals, possibly leading to a higher overall contribution ${ }^{(4)}$.

Then, agents' utility function exists in two expressions. In a sense, by choosing the target of the payment individual $i$ chooses which utility function to activate.

- Grey agents have utility function:

$$
U^{i}\left(x_{i}, y_{i}\right)=y_{i}+w x_{i}-c\left(x_{i}\right),
$$

when the payment is direct, whereas their utility function is

$$
U^{i}\left(x_{i}, y_{i}\right)=y_{i}-c\left(x_{i}\right),
$$

under an indirect payment. But we clearly observe that $\forall x_{i}$, direct payment strictly dominates indirect payment, hence $x_{1}^{C}=$ $x_{1}^{D}$. The choice treatment encourages contribution from grey agents.

- Green agents choose between:

$$
U^{i}\left(x_{i}, y_{i}\right)=y_{i}+w x_{i}+a\left(w+\varepsilon_{D}\right) x_{i}-c\left(x_{i}\right),
$$

when the payment is direct, and

$$
U^{i}\left(x_{i}, y_{i}\right)=y_{i}+a\left(2 w+\varepsilon_{I}\right) x_{i}-c\left(x_{i}\right),
$$

if the payment is indirect. Since $a\left(2 w+\varepsilon_{I}\right)>w+a\left(w+\varepsilon_{D}\right)$, $\forall x_{i}$ indirect payment strictly dominates direct payment, therefore $x_{2}^{C}=x_{2}^{I}$, and the choice treatment minimizes the countervailing effect of external incentives on green agents.

It should be noted that the evaluation of environmental impact varies depending on the destination of money. This could be discussed. Some may hold that the mechanism indicates a value that could remain the same, say some $t_{C}^{*}$, whatever the destination of money. And conversely, others may contend that the association has access to a more efficient process to preserve the environment. We opt for this second possibility.

In aggregate:

$$
X^{C}=n_{1} x_{1}^{D}+n_{2} x_{2}^{I},
$$

and we can express the condition under which the choice treatment avoids an aggregate crowding-out effect:

$$
X^{C} \leq X^{N} \Longleftrightarrow n_{1} x_{1}^{D} \leq n_{2}\left(x_{2}^{N}-x_{2}^{I}\right)
$$

\footnotetext{
${ }^{(4)}$ Moreover, in addition to obvious intuitive reasons based on empirical evidence, we argue that people enjoy the possibility of choosing by themselves, even at a cost (Benz et al., 2004; Frey and Stutzer, 2005). This is conceptualized through the idea of 'procedural utility'.
} 
Two last remarks are worth noting. Firstly, under the maintained assumption that $a\left(2 w+\varepsilon_{I}\right)>w+a\left(w+\varepsilon_{D}\right)$, the choice treatment reveals the agents' type and thus the 'color' of its contribution: having observed than an agent has chosen the direct payment (resp. the indirect payment) one can deduce that this agent is grey (resp. green). Secondly, the higher the payment $w$, the closer $a\left(2 w+\varepsilon_{I}\right)$ to $a t^{*}$, and we may observe $X^{C}>X^{N}$ and $X^{I}<X^{D}$. Overall, the choice treatment is the best mode of external intervention (except may be when compared to no intervention at all), because it unambiguously fosters grey contributions while at the same time it minimizes the risk to erode the intrinsic motivations embedded in green contributions.

\section{EMPIRICAL ANALYSES}

4.1. Testable predictions. The purpose of the previous conceptual framework was to organize thinking on the issue of the present article, before turning to the empirical analysis. This simple theory of behaviors conveys general qualitative predictions, that empirical analyses can test and possibly refute:

- Prediction 1: When an environmental-related intrinsic motivation pre-exists, a newly and 'weak' monetary reward crowds out this pre-existing motivation, leading to an overall reduction of the motivation to act and hereafter to an overall decrease in contribution.

- Prediction 2: A monetary reward that is not targeted directly at the individual but at the cause supported by the individual's behavior counteracts the crowding-out effect of a direct monetary reward.

- Prediction 3: When a choice is given between a direct and an indirect incentive, the overall contribution is higher than without choice at the same level of incentive.

4.2. Experimental design. In order to investigate the above predictions, we designed a questionnaire regarding pro-environmental behaviors. In January 2009, the survey was administered to a randomly selected sample of 1498 French citizens living in the Montpellier metropolitan area (South of France). This metropolitan area was chosen because of highly publicized events and initiatives promoting individual and collective behavioral changes to help the environment. The proenvironmental behaviors surveyed are very common such as switching off the light when leaving a room, turning off tap when brushing teeth, using a re-usable grocery bag or purchasing ecofriendly products. These items were informed on a Likert scale from 'never' to 'always'.

Every participant received an envelope containing the one-page questionnaire, an accompanying letter describing the overall study and presenting the incentive offered (depending on the treatment), a reply 
coupon and a prepaid return envelope. In the test phase, reading the accompanying letter and filling the questionnaire took on average 6 mns. We wrote the letter of solicitation to make it engaging, easy to read and promoting the benefits of results for the common good. In order to activate intrinsic pro-environmental motives, we used a double strategy, first by stressing in the accompanying letter that a better knowledge of pro-environmental behaviors can inform policy makers and researchers and second, by committing ourselves to offset for $\mathrm{CO}_{2}$ emissions corresponding to $300 \mathrm{kms}$ by car for each returned questionnaire. The letter was identical across treatments except for the variables (incentive level, money recipient) that changed from one treatment to another.

Our experimental design allows us to compare response rates under different treatments combining the incentive level (no reward, small reward, high reward) for filling and returning the questionnaire and the money recipient (the individual, the 'environmental cause', choice between either the individual or the 'environmental cause'). Exactly as in the analytical framework above, the treatments have been labeled either as 'direct' if the money is offered to the respondent himself or 'indirect' if the money is devoted to the environmental cause or 'chosen' if the respondent must choose between himself and the environmental cause. The incentive levels were chosen to be as realistic as possible. For example, the lower level corresponds to the minimum wage rate in France based on an estimation of the average time spent to fill and send back the questionnaire. We used three levels of incentive:

- a 'no reward' situation to control for the level of intrinsic motivation;

- a 2 euros $(\approx$ US $\$ 3)$ incentive corresponding to the small incentive level;

- a 7 euros $(\approx$ US $\$ 10)$ incentive corresponding to the high incentive level.

We sent 1498 questionnaires which were divided randomly into seven groups of 214 contacts each group corresponding to one of the seven experimental treatments presented in Table 1 below. Due to a poor update of the phone book data and a high turnover in the region surveyed, 380 letters were returned by postal services, stipulating that the person targeted does no longer live at the indicated address at the delivery time. 
Table 1. Experimental treatments.

\begin{tabular}{|c|c|c|c|c|}
\hline Name & Treatment & Amount given (euros) & Reward directed to & N=1118 \\
\hline \hline N & No reward & 0 & Nobody & 157 \\
\hline D2 & Direct reward & 2 & Respondent & 160 \\
\hline D7 & Direct reward & 7 & Respondent & 165 \\
\hline I2 & Indirect reward & 2 & Association & 161 \\
\hline I7 & Indirect reward & 7 & Association & 157 \\
\hline C2 & Chosen reward & 2 & Respondent or Association & 155 \\
\hline C7 & Chosen reward & 7 & Respondent or Association & 163 \\
\hline
\end{tabular}

After receiving all the responses, we purchased environmental offsets from an environmental association for CO2 emissions (US \$733) corresponding to the questionnaires returned, sent back to participants their rewards (US \$612) and made a donation to an environmental association (US \$806).

4.3. Results and discussion. Between January and March 2009, we received 279 responses. The corrected overall response rate reaches $24.96 \%$. No reminder has been sent, to avoid introducing a bias. Table 2 provides key statistics for the seven incentives schemes.

We compare the participation rates under different treatments and table 3 presents the one-tailed z-test for the comparison of two proportions from independent samples that we performed. Most results exposed below are consistent with findings of previous studies.

Table 2. Key statistics.

\begin{tabular}{|c|c|c|c|c|c|}
\hline Treatment & $\begin{array}{c}\text { Response } \\
\text { rate }\end{array}$ & $\begin{array}{c}\text { Women/Men } \\
\text { ratio }\end{array}$ & $\begin{array}{c}\text { Age } \\
\text { (years) }\end{array}$ & $\begin{array}{c}\text { No high school } \\
\text { diploma (\%) }\end{array}$ & $\begin{array}{c}\text { University } \\
\text { education } \\
\text { (years) }\end{array}$ \\
\hline \hline $\mathrm{N}$ & 28.66 & 57.78 & 54.93 & 20.00 & 3.46 \\
\hline $\mathrm{D} 2$ & 19.38 & 64.52 & 45.45 & 12.90 & 4.50 \\
\hline $\mathrm{D} 7$ & 27.27 & 66.67 & 45.36 & 15.56 & 3.49 \\
\hline $\mathrm{I} 2$ & 21.74 & 60.61 & 53.74 & 20.00 & 3.31 \\
\hline $\mathrm{I} 7$ & 24.20 & 51.35 & 53.58 & 13.16 & 4.25 \\
\hline $\mathrm{C} 2$ & 23.87 & 72.22 & 51.31 & 27.03 & 4.25 \\
\hline $\mathrm{C} 7$ & 29.45 & 64.58 & 46.21 & 27.08 & 3.73 \\
\hline TOTAL & 24.96 & 62.55 & 50.01 & 19.71 & 3.82 \\
\hline
\end{tabular}


Table 3. Econometric tests.

\begin{tabular}{|c|c|c|c|c|c|c|c|}
\hline $\begin{array}{c}\text { Test } \\
\text { number }\end{array}$ & $\begin{array}{c}\text { Treatments } \\
\text { compared } \\
X-Y\end{array}$ & $\begin{array}{c}\text { Value X } \\
(\%)\end{array}$ & $\begin{array}{c}\text { Value Y } \\
(\%)\end{array}$ & $\begin{array}{c}\text { Difference } \\
\text { X-Y }(\%)\end{array}$ & z-value & $\operatorname{Pr}\left(Z_{i z}\right.$ ) & $\begin{array}{c}\text { Significant } \\
\text { difference? }\end{array}$ \\
\hline \hline 1 & N-D2 & 28.66 & 19.38 & 9.29 & 1.9365 & 0.0264 & YES** \\
\hline 2 & I2-D2 & 21.74 & 19.38 & 2.99 & 0.6663 & 0.2526 & NO \\
\hline 3 & C2-D2 & 23.87 & 19.38 & 5.12 & 1.1104 & 0.1334 & NO \\
\hline 4 & C2-I2 & 23.87 & 21.74 & 2.13 & 0.4517 & 0.3258 & NO \\
\hline 5 & N-D7 & 28.66 & 27.27 & 1.39 & 0.2778 & 0.3906 & NO \\
\hline 6 & N-I7 & 28.66 & 24.20 & 4.46 & 0.8958 & 0.1852 & NO \\
\hline 7 & N-I2 & 28.66 & 21.74 & 6.92 & 1.4225 & 0.0774 & YES* \\
\hline 8 & N-C2 & 28.66 & 23.87 & 4.79 & 0.9614 & 0.1682 & NO \\
\hline 9 & N-C7 & 28.66 & 29.45 & -0.79 & -0.1547 & 0.5615 & NO \\
\hline
\end{tabular}

* : significant at the $10 \%$ level / ** : significant at the $5 \%$ level

First, consistently with Prediction 1, the findings clearly show that there is a crowding-out effect of a small monetary incentive on participation. When a monetary reward is offered, participation falls by $32.4 \%$ when compared to the benchmark case without reward. This result is significant at the $5 \%$ level $(\mathrm{p}=0.0264)$. Nevertheless, when the monetary incentive is sufficiently high the price effect attenuates the crowding-out effect leading to a lower decrease of participation rate, when compared with the non-reward case $(-4.8 \%)$.

Second, with regard to Prediction 2, offering the incentives to the cause instead of directing it at the individual encourages participation, resulting in an increase by $15.4 \%$ when compared to the case with a direct incentive. However, this result is not significant at the $5 \%$ level $(\mathrm{p}=0.2526)$. The most surprising result is that directing the reward (regardless of its amount) to the cause still engenders a crowding-out effect, reducing participation by $24.1 \%$ when compared to the case without reward. This result is significant at the $10 \%$ level $(p=0.0774)$. An increase of the size of the monetary reward increases participation, but not significantly, by $11.3 \%(\mathrm{p}=0.3007)$ when compared to the small monetary reward directed to the cause, but it still corresponds to a decrease in participation by $15.6 \%(\mathrm{p}=0.1852)$ when compared to the benchmark case.

As for Prediction 3, when the choice is offered to individuals between a direct and an indirect reward, participation increases when compared to both cases with direct $(+26.4 \%)$ or indirect $(+9.8 \%)$ reward but differences are not significant (respectively $\mathrm{p}=0.1334$ and $\mathrm{p}=0.3258$ ). Without offering the choice, we induced a selection bias by attracting either money-motivated individuals or intrinsically motivated individuals. By offering the choice, we can, to some extent, reduce this bias by recruiting in the two types. Individuals may also value the fact of 
having a choice per se which would be consistent with the theory of procedural utility (Benz et al., 2004; Frey and Stutzer, 2005).

4.3.1. Relative performance of the different incentive schemes. If we compare the different incentive schemes in terms of cost-effectiveness, the findings are astonishing. The only incentive scheme that allows a no-decrease (slight increase, but not statistically significant) in participation corresponds to the experimental treatment $\mathrm{C} 7$ where a higher reward is offered along with the choice of its recipient. The marginal cost of this increase in participation rate reaches the huge value of 383. Most of this marginal cost (285) is directed by respondents to the environmental cause, which can be considered as an additional component of effectiveness. Intuitively, rewards devoted to the environmental causes are more likely to be used for environmental improvement than direct rewards offered to individuals. In sum, in all other cases, even if there are (beneficial?) transfers to the environmental cause, these expenditures reduce the response rate when compared to the no-reward case.

4.3.2. Heterogeneity of the green and grey contributions. At this stage, we check whether individuals responding to various treatments differ in terms of socio-demographic characteristics. Indeed, we assume that all original subsamples have similar socio-demographic characteristics because they are randomly drawn from the same whole population. At first glance, we contend that polar treatments will recruit either socalled green contributors or so-called grey contributors. For instance, the neutral treatment $\mathrm{N}$ (i.e., no payment at all) is likely to attract only green contributors while the treatment D2 (i.e., paying a small amount to the individual) is likely to attract mostly grey contributors. In short, can we distinguish green and grey contributors on key sociodemographic variables? This issue is important because it provides insights on how to tailor incentives instruments to avoid a one-size-fits-all strategy and increase the overall effectiveness of policy. If these sociodemographic variables constitute good 'predictors' of individual's type (i.e., green versus grey), they can inform policy makers to target different groups of the whole population. In order to investigate this issue, we performed a Student's independent two-sample t-test with unequal sample size and unequal variance on three available socio-demographic variables, which are gender, age and education level (Table 4).

Table 4. Tests of heterogeneity.

\begin{tabular}{|c|c|c|c|c|c|c|}
\hline $\begin{array}{c}\text { Test } \\
\text { number }\end{array}$ & $\begin{array}{c}\text { Variable } \\
\text { of interest }\end{array}$ & GREY $=\mathrm{D} 2$ & GREEN $=\mathrm{N}$ & t-value & p value & $\begin{array}{c}\text { Significant } \\
\text { difference? }\end{array}$ \\
\hline \hline 1 & age (years) & 45.45 & 54.93 & -2.2564 & 0.0137 & YES** \\
\hline 2 & sex (\% women) & 64.52 & 57.78 & 0.5870 & 0.2796 & NO \\
\hline 3 & study (years) & 3.767 & 2.545 & 1.8700 & 0.0330 & YES** \\
\hline
\end{tabular}


* : significant at the $10 \%$ level / ** : significant at the $5 \%$ level / $* * *$ : significant at the $1 \%$ level

According to Table 4, individuals who responded to treatment D2 are 45.45 years old on average, while individuals who responded to treatment $\mathrm{N}$ are 54.93 years old on average. This difference is significant at the $5 \%$ level $(\mathrm{p}=0.0137)$. Interestingly, grey contributors are younger and more educated when compared with green contributors and these differences are significant at $5 \%$ level $^{(5)}$. Nevertheless, these results are only suggestive, given that we do not have robust information about non-respondents.

A relevant follow-up of this study could be applied to a population for which socio-demographic variables are directly observable or accessible in order to obtain information on non-respondents. This important result supports our idea that studying heterogeneity among agents is relevant when considering intrinsic motivation levels related to the environment. It directly suggests that in order to increase the overall contribution to an environmental public good monetary incentives should be directed to younger individuals who studied longer, and intrinsic motivation reinforcers should be targeted at older people who studied for a shorter time. When incentives are applied, a careful look must be given at the relative size of green and grey contributions made by the population targeted. Lastly, even with the same population, the proportions of green and grey contribution could vary depending on the area/domain of interest, or could even vary over time.

\section{Policy implications And CONCLUding REMARKS}

Does directing monetary incentives to the cause reduce crowdingout? The answer is a conditional 'yes'. Indeed, the negative impact of crowding-out is reduced (but not completely canceled) when money is directed to the cause compared to cases where the money is directed to individuals. Interestingly, the negative impact is most reduced when offering the choice to the respondent between directing a large reward to the cause or to himself. Such an increase in participation can be explained by at least two non-mutually exclusive ways: (i) both types of individuals, intrinsically motivated and extrinsically motivated, can be recruited according to their own preferences, thereby avoiding a counterproductive selection bias, and (ii) intrinsic motivation can even be

\footnotetext{
${ }^{(5)}$ These results still hold if we group together some similar treatments. For instance, the results remain consistent if we add people responding when a small amount is directed to the cause (I2) to the green contributors group. If we add people responding under the choice treatments $(\mathrm{C} 2$ and $\mathrm{C} 7)$ and directing the money to the cause to the green group and those directing the money to themselves to the grey group, the results still hold. The results of these tests are available upon request.
} 
fostered by the fact that a 'greedy' alternative is offered, making the choice of directing the money to the cause appear even more altruistically motivated.

Moreover, given that filling a questionnaire is supposedly performed in total privacy, we deduce that the decision to participate does not rely mostly on social pressures (Ariely et al., 2009). Individuals can be intrinsically motivated by the activity in itself, contributing to better environmental research, policy design or at least helping researchers, regardless of the field considered. It is thus rather tempting for an economist to hope that offering a monetary incentive will lead to a higher participation. Surprisingly, offering a non-negligible monetary incentive ( 2 euros for 6 minute task) is counter-productive, as it reduces spontaneous cooperation. In the absence of any monetary reward, the monetary motivation is not at stake when making the choice to fill the questionnaire or not. Introducing the monetary incentive to encourage participation seems to interact with other pre-existing intrinsic motivations and can trigger a 'market instinct' under which an individual expresses personal interests rather than social preferences (Reeson and Tisdel, 2008). The individual does not consider the question "Am I willing to contribute freely to this survey for the sake of the society and the environment?" but he switches to the question "Am I willing to earn 2 euros to contribute to this survey?" which recruits a different scope of motivations.

When participation rests mainly on intrinsic motivations, there is a clear need to preserve them. It seems that monetary incentives regardless of their end-recipient can undermine these intrinsic motivations, even if the money is offered to the cause. Nevertheless, the extent to which intrinsic motivations are harmed by monetary incentives is not the same according to the recipient. Directing monetary incentives to the cause can quasi-cancel the decrease in overall contributions, but will not generate an improvement compared to a situation without monetary incentives. So, even careful manipulation of monetary incentives must be considered with caution because they can inadvertently stimulate 'market instinct' which has a detrimental effect on intrinsic motivations.

In sum, there is a clear need to identify domains where intrinsic motivations play a role in people behaviors to avoid a 'a-one-size-fitsall' strategy by recommending the use of monetary incentives which can have detrimental effect on the desirable behaviors. Moreover, once caused this effect is contagious and lasting. For instance, it is very plausible that excessive use of monetary incentives with farmers has seriously crowded out their intrinsic motivations in the environmental realm. Rather than just advocating that monetary incentives can generate counter-productive effects, investigating the conditions likely to stimulate and reinforce intrinsic motivations offer a promising avenue 
for future research. An interesting extension to this study will be to use gifts rather than money per se which can avoid to stimulate a detrimental 'market instinct', and directing them either to the individual or to the cause.

\section{REFERENCES}

[1] D. Ariely, Predictably Irrational: The Hidden Forces That Shape Our Decisions, Harper, 2008.

[2] D. Ariely, A. Bracha, S. Meier, Doing Good or Doing Well? Image Motivation and Monetary Incentives in Behaving Prosocially, American Economic Review. 99 (2009) 544-555.

[3] R. Bénabou, J. Tirole, Incentives and Prosocial Behavior, The American Economic Review. 96 (2006) 1652-1678.

[4] M. Benz, B.S. Frey, A. Stutzer, Introducing Procedural Utility: Not Only What, but Also How Matters, Journal of Institutional and Theoretical Economics JITE. 160 (2004) 377-401.

[5] F. Bolle, P.E. Otto, A Price Is a Signal: on Intrinsic Motivation, Crowding-out, and Crowding-in, Kyklos. 63 (2010) 9-22.

[6] S. Bowles, Policies Designed for Self-Interested Citizens May Undermine "The Moral Sentiments": Evidence from Economic Experiments, Science. 320 (2008) 1605.

[7] E.L. Deci, R. Koestner, R.M. Ryan, A Meta-Analytic Review of Experiments Examining the Effects of Extrinsic Rewards on Intrinsic Motivation,, Psychological Bulletin. 125 (1999) 627-668.

[8] D. Dickinson, M. Villeval, Does monitoring decrease work effort?: The complementarity between agency and crowding-out theories, Games and Economic Behavior. 63 (2008) 56-76.

[9] A. Falk, Gift Exchange in the Field, Econometrica. 75 (2007) 1501-1511.

[10] B.S. Frey, R. Jegen, Motivation Crowding Theory, Journal of Economic Surveys. 15 (2001) 589-611.

[11] B.S. Frey, F. Oberholzer-Gee, The Cost of Price Incentives: An Empirical Analysis of Motivation Crowding- Out, The American Economic Review. 87 (1997) 746-755.

[12] B.S. Frey, A. Stutzer, Beyond Outcomes: Measuring Procedural Utility, Oxford Economic Papers. 57 (2005) 90-111.

[13] U. Gneezy, A. Rustichini, A Fine Is a Price, The Journal of Legal Studies. 29 (2000) $1-17$.

[14] C. Mellström, M. Johannesson, Crowding Out in Blood Donation: Was Titmuss Right?, Journal of the European Economic Association. 6 (2008) 845-863.

[15] A.F. Reeson, J.G. Tisdell, Institutions, motivations and public goods: An experimental test of motivational crowding, Journal Of Economic Behavior and Organization. 68 (2008) 273-281.

[16] R.M. Titmuss, The gift relationship: From human blood to social policy, Allen and Unwin, 1970.

[17] B. Vollan, Socio-ecological explanations for crowding-out effects from economic field experiments in southern Africa, Ecological Economics. 67 (2008) 560-573. 
SupAgro, UMr lameta, 2 place Viala, 34060 Montpellier cedex 1. FRANCE

E-mail address: beretti@supagro.inra.fr

INRA, UMr LAMETA, 2 place Viala, 34060 Montpellier cedex 1. FRANCE

E-mail address: figuiere@supagro.inra.fr

SupAgro, UmR lameta, 2 place Viala, 34060 Montpellier cedex 1. FRANCE

E-mail address: grolleau@supagro.inra.fr 


\title{
Documents de Recherche parus en $2011^{1}$
}

\author{
DR n²011 - 01 : Solenn LEPLAY, Sophie THOYER \\ «Synergy effects of international policy instruments to reduce \\ deforestation: a cross-country panel data analysis » \\ DR n²011 - 02 : Solenn LEPLAY, Jonah BUSCH, Philippe DELACOTE, Sophie \\ THOYER \\ « Implementation of national and international REDD \\ mechanism under alternative payments for environemtal \\ services: theory and illustration from Sumatra » \\ DR n²011 - 03 : $\quad$ Stéphanie AULONG, Robert KAST \\ «A conceptual framework to assess vulnerability. Application to \\ global change stressors on South Indian farmers » \\ DR n²011 - 04 : Nicolas QUEROU, Raphael SOUBEYRAN \\ « Voting Rules in Bargaining with Costly Persistent Recognition » \\ DR n²011 - 05 : $\quad$ Pierre COURTOIS, Rabia NESSAH, Tarik TAZDAÏT \\ «How to play the games? Nash versus Berge behavior rules» \\ DR n²011 - 06 : Pierre COURTOIS, Tarik TAZDAÏT \\ « Learning to trust strangers: an evolutionary perspective » \\ DR n²011 - 07 : $\quad$ Pierre COURTOIS, Tarik TAZDAÏT \\ « Bargaining over a climate deal: is it worse to wait and see? » \\ DR n²011 - 08 : Mathieu COUTTENIER, Raphael SOUBEYRAN \\ « Diplomatic Intervention in Civil War: Trade for All or Trade for \\ One?» \\ DR n²011 - 09: Edmond BARANES, Jean-Christophe POUDOU \\ «Internet access and investment incentives for broadband service \\ providers » \\ DR n²011 - 10 : Sadek MELHEM, Michel TERRAZA, Mohamed CHIKHI \\ «Cyclical Mackey Glass Model for Oil Bull Seasonal »
}

\footnotetext{
${ }^{1}$ La liste intégrale des Documents de Travail du LAMETA parus depuis 1997 est disponible sur le site internet : http://www.lameta.univ-montp1.fr
} 
DR n²011 - 11: Marianne LEFEBVRE, Sophie THOYER, Mabel TIDBALL, Marc WILLINGER

«Sharing rules for a Common-Pool Resource with private alternatives »

DR n²011-12: $\quad$ Ahmed ENNASRI, Marc WILLINGER

«Managerial incentives under competitive pressure: Experimental investigation »

DR n²011 - 13: Sadek MELHEM, Abdul Salam DIALLO, Michel TERRAZA

« Hypothesis of Currency Basket Pricing of Crude Oil: An Iranian Perspective »

DR n²011 - 14 : Marianne LEFEBVRE, Lata GANGADHARAN, Sophie THOYER

«Do Security-differentiated Water Rights Improve Efficiency? »

DR n²011 - 15: Antoine BERETTI, Charles FIGUIERES, Gilles GROLLEAU

« Using Money to Motivate Both 'Saints' and 'Sinners' : A Field

Experiment On Motivational Crowding-Out» 
Contact :

Stéphane MUSSARD : $\quad$ mussard@lameta.univ-montp1.fr 


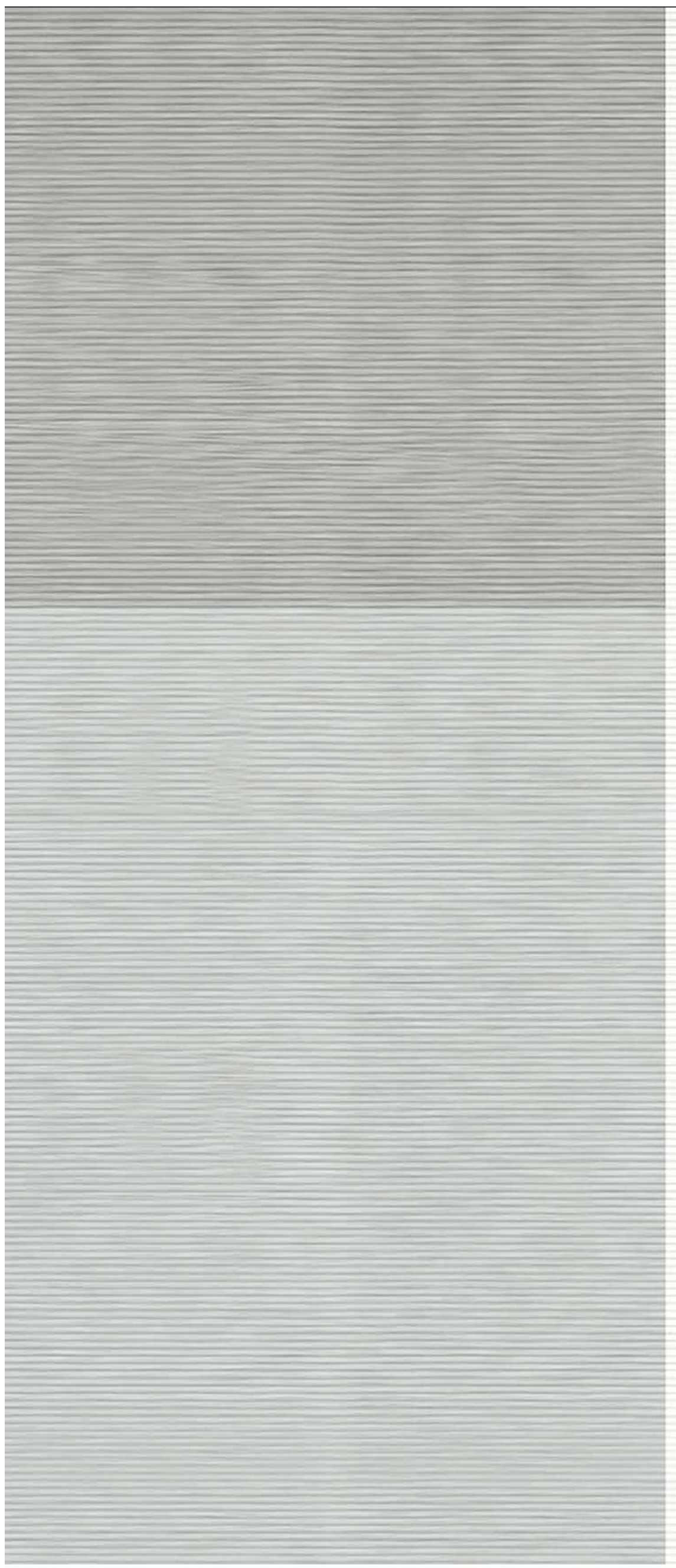

